\title{
Free Radical Scavenging and Inhibition of Nitric Oxide Synthase Potentiates the Neurotrophic Effects of Brain-Derived Neurotrophic Factor on Axotomized Retinal Ganglion Cells In Vivo
}

\author{
Nikolaj Klöcker, ${ }^{1}$ Alessandro Cellerino, ${ }^{2}$ and Mathias Bähr ${ }^{1}$ \\ Departments of ${ }^{1}$ Neurology and ${ }^{2}$ Ophthalmology, University of Tübingen, 72076 Tübingen, Germany
}

Brain-derived neurotrophic factor (BDNF) partially promotes the survival of axotomized retinal ganglion cells (RGCs). In analogy with in vitro experiments (Koh et al., 1995; Samdami et al., 1996), we tested whether neuroprotection by BDNF is limited by adverse effects as a consequence of excessive free radical formation. First, we investigated whether BDNF and the free radical scavenger $N$-tert-butyl-(2-sulfophenyl)-nitrone (S-PBN) cooperate in protecting RGCs from axotomy-induced death. Although systemic S-PBN treatment alone did not influence RGC survival after axotomy, it potentiated the neuroprotective effects of BDNF significantly. Single BDNF treatment rescued $27 \%$ of the RGCs, which otherwise would have died $14 \mathrm{~d}$ after optic nerve transection, whereas a combined treatment of BDNF and S-PBN improved this rescue rate up to $68 \%$. We then investigated whether the adverse effects of BDNF could be ascribed to activation of nitric oxide synthase (NOS). We found colocalization of NOS and the BDNF receptor TrkB in the retina. NADPH-diaphorase reactivity, a reliable marker for NOS in the rat retina, increased after chronic BDNF treatment in vivo. Systemic application of the NOS-inhibitor $N$ - $\omega$-nitro-L-argininemethylester (L-NAME) potentiated the neuroprotective action of BDNF (55\% rescue rate). We conclude that activation of NOS is a pathological consequence of BDNF application, which reduces its neuroprotective potential. The observation that this adverse effect can be antagonized by systemic application of free radical scavengers could be of relevance for clinical applications of neurotrophins in human neurodegenerative diseases.

Key words: BDNF; S-PBN; apoptosis; excitotoxicity; free radical scavenger; nitric oxide; retina; axotomy; neurodegeneration
Transection of the rat optic nerve $(\mathrm{ON})$ induces retrograde death of $\sim 80 \%$ of retinal ganglion cells (RGCs) within 2 weeks (Villegas-Pérez et al., 1988, 1993; Mansour-Robaey et al., 1994). It had been suggested that axotomized RGCs die as a result of deprivation of target-derived trophic support, but studies by Perry and Cowey (1982) and Carpenter et al. (1986) later demonstrated that the survival of unlesioned adult rat RGCs is largely independent of target-derived trophic factors. However, application of several neurotrophic factors has been shown to promote survival of axotomized RGCs (Sievers et al., 1987; Carmignoto et al., 1989; Mey and Thanos, 1993; Huxlin et al., 1995). Despite the fact that brain-derived neurotrophic factor (BDNF) (Barde et al., 1982; Leibrock et al., 1989) is not required for RGC survival during development (Cellerino et al., 1997b), it promotes survival of RGCs in a variety of experimental lesion models both in vitro and in vivo (Johnson et al., 1986; Thanos et al., 1989; Mey and Thanos, 1993; Mansour-Robaey et al., 1994; Cui and Harvey, 1995; Meyer-Franke et al., 1995; Peinado-Ramón et al., 1996). This is in good agreement with the finding that RGCs express the BDNF receptor TrkB (Jelsma et al., 1993; Barbacid, 1994; Rickman and Brecha, 1995; Cellerino and Kohler, 1997). The neuroprotective effect of BDNF is probably mediated by delaying apoptotic death of RGCs (Cui and Harvey, 1995) induced by ON

Received Aug. 8, 1997; revised Oct. 20, 1997; accepted Nov. 6, 1997.

This work was supported by the Bundesministerium für Bildung, Wissenschaft, Forschung und Technologie (Neurotraumatologie and Grant 01 KS 9602 to N.K.) and European Community Grant ERBCHBGCT 940745 to A.C. M.B. holds a Herrmann-and-Lilly-Schilling Foundation professorship. We thank S. Thomsen for her technical assistance and M. Rott for his helpful comments on this manuscript.

Correspondence should be addressed to Mathias Bähr, Department of Neurology, University of Tübingen, Hoppe-Seyler-Strasse 3, 72076 Tübingen, Germany.

Copyright (C) 1998 Society for Neuroscience $0270-6474 / 98 / 181038-09 \$ 05.00 / 0$ transection (Garcia-Valenzuela et al., 1994; Harvey et al., 1994; Rabacchi et al., 1994; Isenmann et al., 1997).

However, BDNF neuroprotection in vivo is transient. Even repeated intraocular injections of BDNF cannot assure long-term survival of axotomized RGCs (Mansour-Roubaey et al., 1994). It is possible that BDNF downregulates TrkB expression and thereby reduces the responsiveness to BDNF in RGCs, as has been observed in other neurons (Carter et al., 1995; Frank et al., 1996). An alternative explanation is that BDNF-mediated neuroprotection is limited by adverse side effects. In in vitro experiments, for instance, Koh et al. (1995) found that BDNF indeed reduced apoptotic but enhanced necrotic cell death of cortical neurons after an excitotoxic insult. Subsequent studies have shown that this adverse effect is caused by an increased formation of free radicals, particularly of nitric oxide (NO) (Samdami et al., 1996).

The aim of the present study was to investigate whether similar adverse effects also reduce the neuroprotective potential of BDNF in vivo. We observed that systemic application of the unspecific free radical scavenger $N$-tert-butyl-(2-sulfophenyl)-nitrone (S-PBN), which attenuates excitotoxic lesions in vivo (Schulz et al., 1995a,b; Kuroda et al., 1996), substantially potentiated BDNF neuroprotection on axotomized RGCs. This is in good agreement with previous in vitro studies showing that the neuroprotective action of trophic factors can be potentiated by antioxidants (Mayer and Noble, 1994). To identify the type of free radicals that limited neuroprotection by single BDNF treatment, we replaced S-PBN by the specific NO synthase (NOS) inhibitor $N$ - $\omega$-nitro-L-argininemethylester (L-NAME). L-NAME also improved neuroprotection by BDNF significantly, suggesting that BDNF limits its own neuroprotective potential by inducing NOS. 


\section{MATERIALS AND METHODS}

ON transection. Adult female Dark Agouty rats (150-200 gm; Charles River Wiga, Sulzfeld, Germany) were anesthetized by intraperitoneal injection of chloral hydrate $(0.42 \mathrm{gm} / \mathrm{kg}$ body weight). After skin incision close to the superior orbital rim, the right orbita was opened, saving the supraorbital vein, and the lacrimal gland was resected subtotally. By means of a small retractor, the superior extraocular muscles were spread, and the $\mathrm{ON}$ was exposed after longitudinal incision of the eye retractor muscle and the perineurium. The right $\mathrm{ON}$ was transected $\sim 2 \mathrm{~mm}$ from the posterior pole of the eye, taking care not to damage the retinal blood supply. The latter was checked by fundoscopy after surgery.

Retrograde labeling of RGCs. To determine RGC densities, cells were labeled retrogradely with the fluorescent tracers $1,1^{\prime}$-dioctadecyl-3,3, $3^{\prime}, 3^{\prime}$ tetramethylindocarbocyanine perchlorate (Di-I; Molecular Probes, Eugene, OR) and fast blue (FB; Dr. Illing Chemie, Gross-Umstadt, Germany). For Di-I staining from the superior colliculi (SC), animals were anesthetized by diethylether at postnatal day 7. At this age, the SC offer good surgical access, because they are not yet overgrown by the visual cortex. The skin was incised mediosagitally, and the skull cartilage was opened dorsal to the lambda fissure. Di-I (5\% in dimethylformamide) was then applied to both superior colliculi using a micropipette. ON transections were performed as described above 10-12 weeks after Di-I labeling. For FB staining, a small piece of gel foam soaked in $2 \%$ aqueous FB was placed at the ocular stump of the ON after axotomy.

Drug administration. Recombinant human BDNF (Alomone Labs) was dissolved in a $1 \%$ solution of bovine serum albumin (BSA) in PBS at three different concentrations of 100,250 , and $1000 \mathrm{ng} / \mu \mathrm{l}$. For intraocular injection of BDNF or vehicle, animals were anesthetized by diethylether. By means of a glass microelectrode with a tip diameter of $30 \mu \mathrm{m}$, $2 \mu \mathrm{l}$ of BDNF (200 and $500 \mathrm{ng}$ and $2 \mu \mathrm{g}$, respectively) in BSA/PBS or 2 $\mu \mathrm{l}$ of $\mathrm{BSA} / \mathrm{PBS}$ without BDNF were injected into the vitreous space puncturing the eye at the cornea-sclera junction. BDNF and vehicle treatment consisted of three intraocular injections on days 4, 7, and 10 after ON transection.

S-PBN (Sigma, Deisenhofen, Germany) was dissolved in PBS at concentrations of $100 \mathrm{mg} / \mathrm{ml}$ (S-PBN 100) and $200 \mathrm{mg} / \mathrm{ml}$ (S-PBN 200). $\mathrm{S}-\mathrm{PBN}$ treatment consisted of intraperitoneal injections of $1 \mathrm{ml} / \mathrm{kg}$ body weight every $12 \mathrm{hr}$ starting $30 \mathrm{~min}$ after ON transection.

L-NAME (Sigma) was dissolved in PBS at a concentration of $25 \mathrm{mg} / \mathrm{ml}$ (L-NAME 25). L-NAME treatment followed the same regimen as described for S-PBN.

$R G C$ densities. Fourteen days after $\mathrm{ON}$ transection, animals received an overdose of chloral hydrate, and both eyes were removed. The retinas were dissected, flat-mounted on glass slides, and fixed in $4 \%$ paraformaldehyde (PFA) in PBS for $20 \mathrm{~min}$. They were examined by fluorescence microscopy (Axiovert 35; Zeiss, Oberkochen, Germany) using a rhodamine filter (546/590 nm) and a 4,6-diaminido-2-phenylindole filter (365/ $397 \mathrm{~nm}$ ) for Di-I and FB fluorescence, respectively. RGC densities were determined by counting tracer-labeled RGCs in 12 distinct areas of $62,500 \mu \mathrm{m}^{2}$ each (three areas per retinal quadrant at three different eccentricities of one-sixth, one-half, and five-sixths of the retinal radius) Cell counts were done in duplicate by two independent investigators according to a double-blind protocol. Because retinal shrinkage attributable to intraocular injections could have resulted in overestimation of RGC densities, we measured the retinal areas of untreated and injected eyes with the aid of an image analysis system (NIH Image 1.44) after drawing the retinas by camera lucida. After $14 \mathrm{~d}$, there was a reduction of $2 \%$ in retinal area of the test eyes injected three times with a volume of $2 \mu \mathrm{l}$ that was statistically not significant.

NADPH-diaphorase histochemistry and TrkB immunohistochemistry. For NADPH-diaphorase reaction and TrkB immunohistochemistry, eyes were dissected and immersion-fixed as eye cups without cornea and lens for $60 \mathrm{~min}$ in $4 \% \mathrm{PFA} / \mathrm{PBS}$ at $4^{\circ} \mathrm{C}$. After fixation, the eyes were immersed in $30 \%$ sucrose and PBS overnight at $4^{\circ} \mathrm{C}$ before $16 \mu \mathrm{m}$ radial cryostat sections were made. The sections were collected on gelatin-coated slides, air-dried, and stored at $-20^{\circ} \mathrm{C}$ until further processing.

The NADPH-diaphorase reaction was performed according to the protocol of Huxlin and Benett (1995). Briefly, after washing with PBS, sections were incubated at room temperature in a solution consisting of $0.5 \mathrm{mg}$ of nitro blue tetrazolium, $2 \mathrm{mg}$ of $\beta$-NADPH, and $6 \mu \mathrm{l}$ of Triton $\mathrm{X}-100$ in $2 \mathrm{ml}$ of PBS (chemicals purchased from Sigma), and the development of the staining was controlled by repeated microscopic inspections. The histochemical reaction was stopped by washing three times in PBS. Sections were coverslipped in 9:1 glycerol/PBS.

BDNF-treated and control retinas were processed in parallel to avoid variability in the histochemical reaction and were understained (60 $\mathrm{min})$ to visualize differences in staining intensity better. When double labeling was performed, sections were stopped after 30,60 , or $120 \mathrm{~min}$ to find the best conditions to visualize NADPH-diaphorase reaction and TrkB immunohistochemistry simultaneously.

For double labeling, sections were first histochemically stained for NADPH-diaphorase reactivity and then preincubated in $30 \%$ normal goat serum (NGS) in PBS containing 0.03\% Triton X-100 (PBST) for 2 $\mathrm{hr}$ at room temperature. Sections were then incubated either with the primary antibody against TrkB (T16030; Transduction Laboratories, Lexington, KY; 1:50 in 5\% NGS/PBST) or with PBS (negative control) at $4{ }^{\circ} \mathrm{C}$ overnight. To visualize anti-TrkB antibody binding, sections were incubated in goat anti-rabbit serum conjugated with $\mathrm{Cy}-3$ (Rockland, Gilbertsville, PA) diluted 1:1000 in a solution of 5\% NGS and PBS for 2-3 hr at room temperature. Sections were coverslipped in 9:1 glycerol/PBS.

Statistics. Data are given as mean \pm SEM. Statistical significance was assessed using the Mann-Whitney- $U$ test for independent samples. For expressing survival-promoting effects we defined RGC rescue rate (RRR) as follows: $\operatorname{RRR}=\left(N_{\text {ther }}-N_{\text {con }}\right) /\left(N_{\text {tot }}-N_{\text {con }}\right) \times 100$, where $N_{\text {tot }}$ is the number of RGCs in unlesioned retinas, $N_{\text {con }}$ is the number of RGCs surviving without therapy, and $N_{\text {ther }}$ is the number of RGCs surviving after a given therapy.

\section{RESULTS}

\section{Fluorescent labeling techniques}

Retrograde labeling of RGCs from the superior colliculus with Di-I revealed a characteristically fine-dotted pattern of fluorescence of the RGC perikarya, whereas retrograde labeling from the axon stump after ON transection with FB showed rather diff use staining of the perikarya. Particularly in the retinal periphery, both fluorescent dyes labeled proximal portions of the dendritic arbors. Fourteen days after ON transection, there was additional labeling of endothelial cells of retinal vessels, which could be distinguished easily by their fusiform shape. Furthermore, we found staining of microglial cells located both in the RGC layer and other retinal layers. These cells varied greatly in morphology, ranging from rod-shaped to rather lumpy but usually showing marked ramification compared with RGCs. Doublestaining protocols with Di-I from the superior colliculus and FB from the axon stump revealed similar label efficiencies of the two tracers, thus allowing comparison of Di-I and FB data (Eschweiler and Bähr, 1993).

\section{Effects of ON transection}

In unlesioned control retinas, the mean RGC density was $2039 \pm$ 56 Di-I labeled cells $/ \mathrm{mm}^{2}$ (Fig. 1, Table 1). RGC density declined with retinal eccentricity from $2647 \pm 95 \mathrm{per} \mathrm{mm}^{2}$ at one-sixth down to $1180 \pm 46$ per $\mathrm{mm}^{2}$ at five-sixths of the retinal radius. ON transection induced secondary death of RGCs. Within $14 \mathrm{~d}$, the mean RGC density decreased to $17 \%$ of the normal control (339 $\pm 43 \mathrm{FB}$ labeled $\mathrm{RGCs} / \mathrm{mm}^{2}$ ). RGC death was more pronounced at the inner and medium retinal radii, with $15 \%$ RGCs surviving compared with $22 \%$ at the outer retinal radius.

\section{Single treatment with S-PBN}

Systemic treatment with the free radical scavenger S-PBN at doses of 100 and $200 \mathrm{mg} / \mathrm{kg}$ twice daily for 2 weeks did not influence RGC survival significantly compared with the untreated control group (Table 1). In animals treated with S-PBN at a dose of $100 \mathrm{mg} / \mathrm{kg}$, the mean RGC density was $300 \pm 45 / \mathrm{mm}^{2}$, whereas in animals treated with S-PBN at a dose of $200 \mathrm{mg} / \mathrm{kg}$, the mean RGC density was $262 \pm 9 / \mathrm{mm}^{2}$.

\section{Single treatment with BDNF}

Intraocular injections of vehicle on days 4, 7, and 10 after ON transection led to a slight but statistically nonsignificant increase 

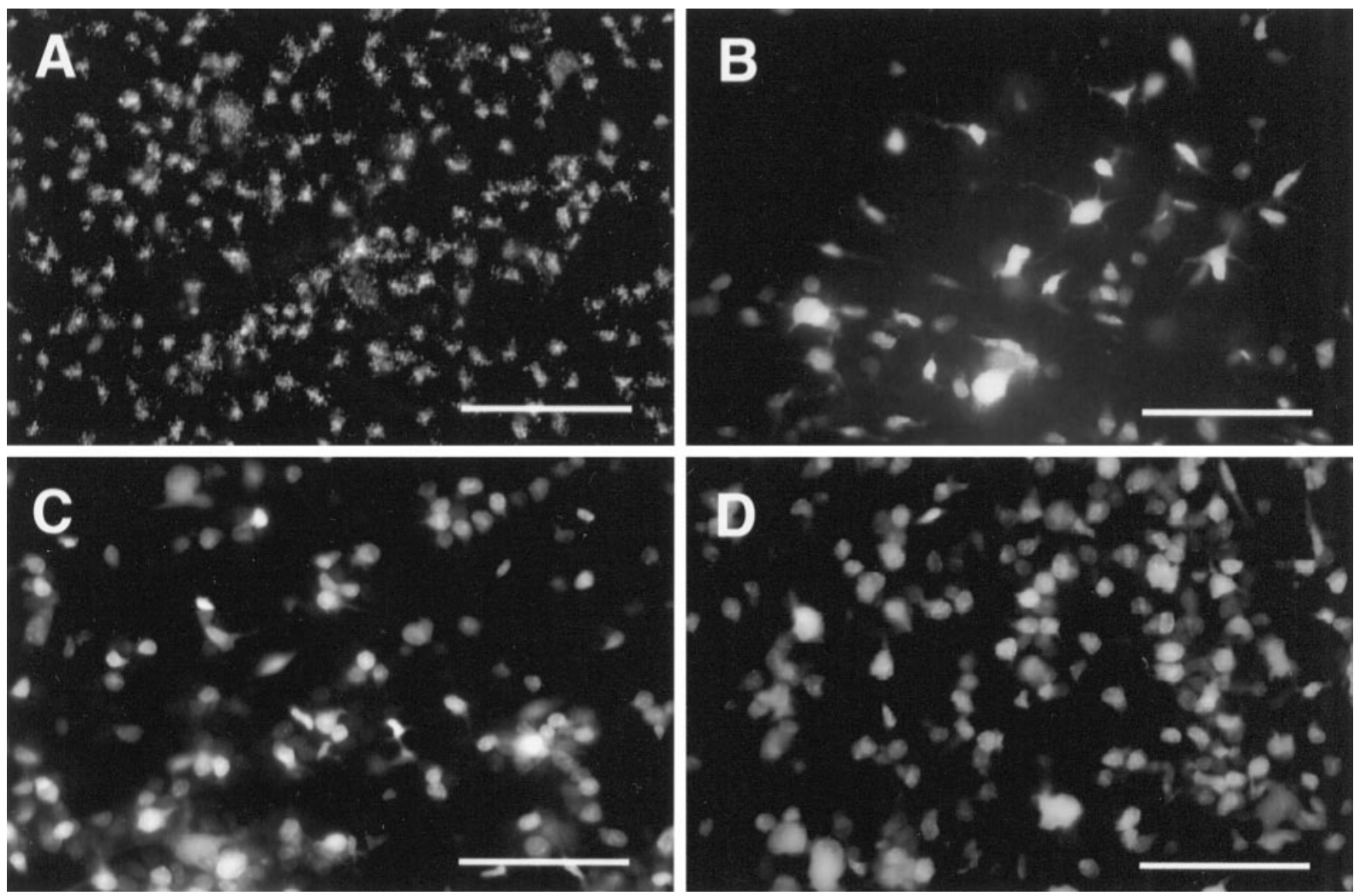

Figure 1. Representative photographs of flat-mounted retinas at corresponding areas (superior temporal quadrant at one-half of the retinal radius) showing Di-I-labeled RGCs in an unlesioned control retina $(A)$ and fast blue-labeled RGCs in retinas $14 \mathrm{~d}$ after ON transection without treatment $(B)$, after three intraocular injections of $500 \mathrm{ng}$ of BDNF repeated on days 4, 7, and 10 after axotomy $(C)$, and after combined treatment with systemic S-PBN $(100 \mathrm{mg} / \mathrm{kg}$ twice daily) and three intraocular injections of $500 \mathrm{ng}$ of BDNF repeated on days 4 , 7, and 10 after axotomy $(D)$. Scale bar, $100 \mu \mathrm{m}$.

in mean RGC density of $412 \pm 77 / \mathrm{mm}^{2}$ (Table 1). Intraocular BDNF, however, enhanced RGC survival significantly in a dosedependent manner (Fig. 1, Table 1). Intraocular injection of 200 ng of BDNF on days 4, 7, and 10 after axotomy resulted in an RRR (see Materials and Methods) of $17 \%(627 \pm 60 \mathrm{RGCs} /$ $\mathrm{mm}^{2}$ ). Increasing the dose of BDNF to $500 \mathrm{ng}$ increased the RRR to $27 \%\left(804 \pm 87 \mathrm{RGCs} / \mathrm{mm}^{2}\right)$. Doses as high as $2000 \mathrm{ng}$ of BDNF failed to improve RGC survival further. Although statistically not significant, the number of surviving RGCs even declined compared with the experimental group treated with $500 \mathrm{ng}$ of BDNF $\left(748 \pm 96 \mathrm{RGCs} / \mathrm{mm}^{2}\right)$. The degree of RGC rescue by intraocular BDNF was dependent on retinal eccentricity (see Fig. 3 ). Referring to the number of RGCs that otherwise would have died without treatment, BDNF rescued 2-2.7 times more RGCs at one-sixth of the retinal radius than at five-sixths of the radius.

\section{Combined treatment with S-PBN and BDNF}

Although a single treatment with S-PBN at $100 \mathrm{mg} / \mathrm{kg}$ did not influence RGC survival $14 \mathrm{~d}$ after $\mathrm{ON}$ transection, it potentiated the survival-promoting effects obtained with intraocular administration of BDNF significantly (Figs. 1, 2, Table 1). S-PBN together with $200 \mathrm{ng}$ of BDNF resulted in an increase in the number of surviving RGCs by a factor of 2.2 compared with controls treated with $200 \mathrm{ng}$ of BDNF alone. The combination of S-PBN with 500 and $2000 \mathrm{ng}$ of BDNF increased the number of surviving RGCs by factors of 2.5 and 1.8, respectively. As observed for single BDNF treatment, neuroprotection by combined treatment depended on retinal eccentricity, again with the greatest $\mathrm{RGC}$ rescue at the inner retinal radius (Fig. 3). However, with increasing BDNF dosage, the synergistic effect of S-PBN was particularly evident at the outer retinal radius.

\section{NOS-positive cells express TrkB}

The BDNF receptor TrkB is expressed not only in RGCs, as mentioned above, but also in some amacrine neurons. TrkBpositive amacrine cells have large somata and are located at the vitreal border of the inner nuclear layer (Rickman and Brecha, 1995; Cellerino and Kohler, 1997). They have the typical morphology of wide-field amacrine cells, similar to that of NOSexpressing amacrine cells (Koistinaho and Sagar, 1995). In rats, NOS-expressing neurons are also present in the ganglion cell layer (Huxlin and Benett, 1995). To determine whether NOSexpressing cells also express the BDNF receptor TrkB, we performed a double-labeling study. We labeled NOS-containing cells by NADPH-diaphorase reaction, a reliable marker of NOSexpressing neurons in the rodent retina (Darius et al., 1995; Roufail et al., 1995). NADPH-diaphorase reactivity was found in cells in the ganglion cell layer and in two subtypes of amacrine neurons in the inner nuclear layer: one strongly labeled subtype with a large soma (type I) and a lighter labeled subtype with a smaller soma (type II). Combination of immunohistochemistry for TrkB with NADPH-diaphorase reaction revealed colocalization in type II amacrine cells and in cells of the ganglion cell layer (Fig. 4). A similar pattern of colocalization was observed when TrkB immunohistochemistry was performed using an immunoperoxidase reaction (data not shown). However, it was not possible to determine whether type I amacrine cells also express TrkB, because immunofluorescent and immunoperoxidase label- 
Table 1. Effects of single and combined treatment with systemic S-PBN or L-NAME and intraocular BDNF on RGC survival 14 days after optic nerve transection in the adult rat

\begin{tabular}{|c|c|c|c|c|}
\hline & $1 / 6$ Retinal radius & $3 / 6$ Retinal radius & $5 / 6$ Retinal radius & Average \\
\hline Normal control & $2647 \pm 95$ & $2289 \pm 53$ & $1180 \pm 46$ & $2039 \pm 56(n=11)$ \\
\hline Axotomy w/o th. & $409 \pm 50$ & $354 \pm 56$ & $254 \pm 49$ & $339 \pm 43(n=6)$ \\
\hline Vehicle & $587 \pm 75$ & $394 \pm 90$ & $255 \pm 77$ & $412 \pm 77(n=4)$ \\
\hline S-PBN 100 & $402 \pm 72$ & $271 \pm 37$ & $228 \pm 27$ & $300 \pm 45(n=6)$ \\
\hline S-PBN 200 & $336 \pm 18$ & $254 \pm 7$ & $196 \pm 13$ & $262 \pm 9(n=6)$ \\
\hline L-NAME 25 & $485 \pm 43$ & $433 \pm 31$ & $340 \pm 27$ & $419 \pm 27(n=4)$ \\
\hline BDNF 200 & $906 \pm 83^{*}$ & $621 \pm 76^{* *}$ & $355 \pm 36$ & $627 \pm 60^{* *}(n=5)$ \\
\hline BDNF $200+$ S-PBN 100 & $1531 \pm 150^{* * * * * *}$ & $943 \pm 95^{* *, * * *}$ & $486 \pm 59 * *$ & $987 \pm 94^{* * * * * *}(n=5)$ \\
\hline BDNF 500 & $1253 \pm 138^{*}$ & $777 \pm 80^{*}$ & $382 \pm 61$ & $804 \pm 87 *(n=7)$ \\
\hline BDNF $500+$ S-PBN 100 & $1988 \pm 175^{* * * * * *}$ & $1624 \pm 167 * *, * * * *$ & $868 \pm 74^{* *, * * * *}$ & $1493 \pm 123 * *, * * * * \quad(n=9)$ \\
\hline BDNF 2000 & $1103 \pm 187^{* *}$ & $749 \pm 88^{* *}$ & $392 \pm 26$ & $748 \pm 96^{* *}(n=4)$ \\
\hline BDNF $2000+$ S-PBN 100 & $1409 \pm 235^{* *}$ & $1147 \pm 197^{* *}$ & $687 \pm 130^{*, * * *}$ & $1081 \pm 169^{* *}(n=4)$ \\
\hline BDNF 500 + L-NAME 25 & $1634 \pm 27^{*, * * *}$ & $1297 \pm 83^{*, * * *}$ & $881 \pm 14^{*, * * *}$ & $1270 \pm 35^{* * * * *}(n=3)$ \\
\hline
\end{tabular}

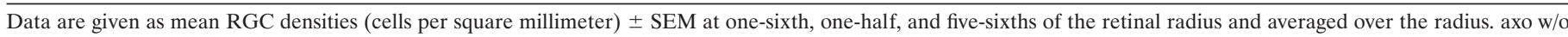

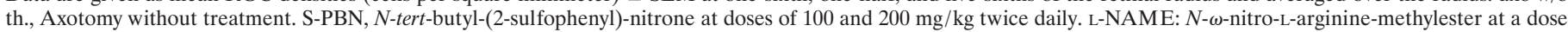

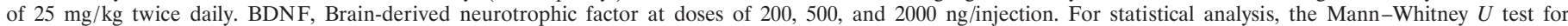
independent samples was used.

$*, * *$ Significant differences from axo w/o th. $\left({ }^{*} p<0.05 ; * * p<0.01\right)$.

$* * *, * * *$ Significant differences from single BDNF treatment $(* * * p<0.05 ; * * * p<0.01$, respectively).

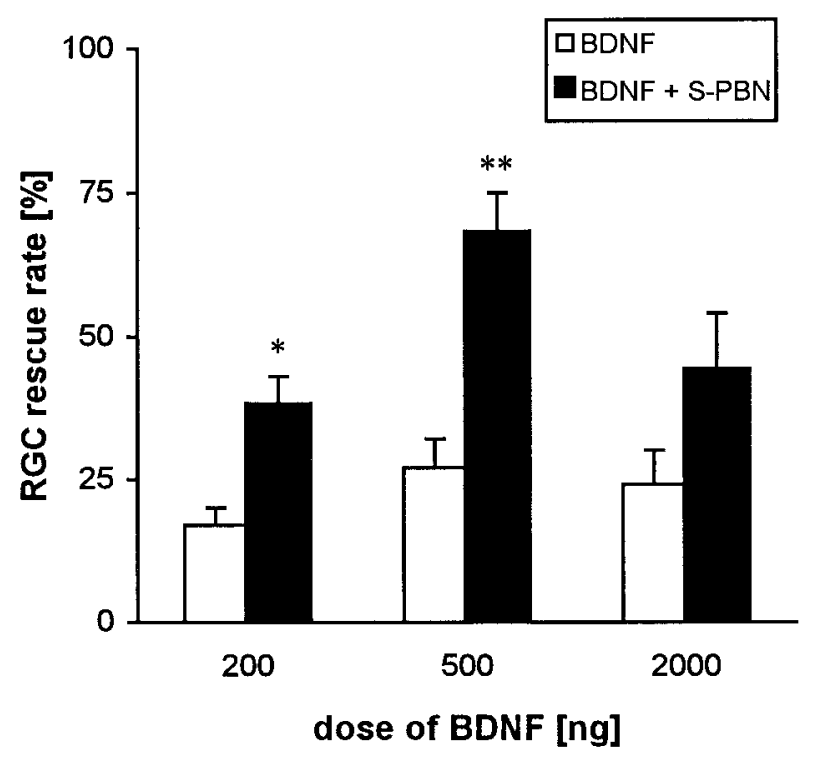

Figure 2. The free radical scavenger S-PBN potentiates the rescue effect of BDNF on axotomized RGCs. BDNF treatment: 3 intraocular injections on days 4, 7, and 10 after axotomy at doses of 200, 500, and $2000 \mathrm{ng} /$ injection. S-PBN treatment: $100 \mathrm{mg} / \mathrm{kg}$ intraperitoneally twice daily. RRR $=\left(N_{\text {ther }}-N_{\text {con }}\right) /\left(N_{\text {tot }}-N_{\text {con }}\right) \times 100$, where $N_{\text {tot }}$ is the number of RGCs in unlesioned retinas, $N_{\text {con }}$ is the number of RGCs surviving without therapy, and $N_{\text {ther }}$ is the number of RGCs surviving after a given therapy. Data are given as mean \pm SEM. Asterisks indicate significant differences between combined and single treatment groups: ${ }^{*} p<0.05 ;{ }^{* *} p<0.01$.

ing for TrkB was always obscured in these cells by the dense formazan precipitates as a consequence of the strong NADPHdiaphorase reactivity.

\section{BDNF enhances NADPH-diaphorase reactivity}

We investigated whether BDNF treatment induces NOS expression in the rat retina. In a first approach, we applied BDNF in normal control animals according to a protocol that has proven to elicit a response in dopaminergic amacrine neurons (Cellerino et al., 1997a). To this end, animals received an intraocular injection of $1000 \mathrm{ng}$ of BDNF every other day. Six days after the first injection, the animals were killed, and the retinas of both eyes were stained for NADPH-diaphorase reactivity. Preparations were coded, and the intensity of NADPH-diaphorase staining was then evaluated by two independent observers. In BDNF-treated retinas, the intensity of NADPH-diaphorase labeling was obviously stronger than in untreated retinas $(n=3)$ (Fig. $5 A, B)$. Vehicle injection, however, did not change NADPH-diaphorase staining visibly (data not shown). In a second set of experiments, we analyzed retinal NADPH-diaphorase histochemical activity $6 \mathrm{~d}$ after ON transection. Although axotomy without further treatment led only to a slight increase in NADPH-diaphorase labeling, a single application of $500 \mathrm{ng}$ of BDNF on day 4 after axotomy enhanced NADPH-diaphorase staining consistently ( $n=3$; Fig. $5 C, D)$. Sham treatment was not different from axotomy without treatment.

\section{Effects of combined treatment with L-NAME and BDNF}

Single treatment with L-NAME at a dose of $25 \mathrm{mg} / \mathrm{kg}$ body weight injected intraperitoneally twice daily led to only a slight but statistically not significant increase in the survival rate of RGCs $14 \mathrm{~d}$ after axotomy (419 $\left.\pm 27 \mathrm{RGCs} / \mathrm{mm}^{2}\right)$ (Table 1). As has been demonstrated for S-PBN, however, systemic administration of L-NAME was able to improve the neuroprotective effects of intraocular BDNF significantly. The RRR obtained with repeated injections of $500 \mathrm{ng}$ of BDNF was increased from 27 to $55 \%$ by combining BDNF treatment with application of L-NAME. As with S-PBN, the synergistic effect of L-NAME on BDNF neuroprotection was most evident at the outer retinal radius (Fig. 3).

\section{DISCUSSION}

BDNF has been shown repeatedly to delay retrograde death of RGCs after ON transection in the adult rat (Mey and Thanos, 1993; Mansour-Robaey et al., 1994; Peinado-Ramón et al., 1996), but this effect is transient. Our study reveals that neuroprotection 


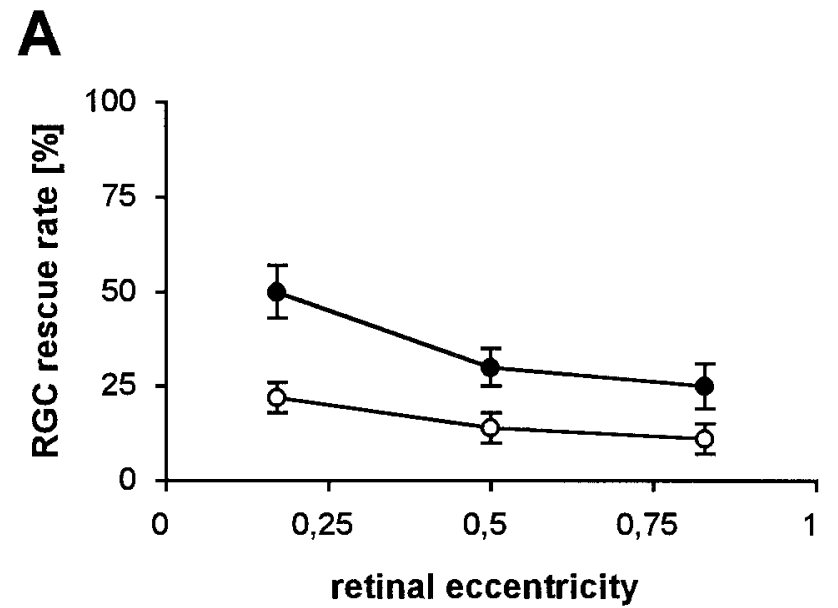

B
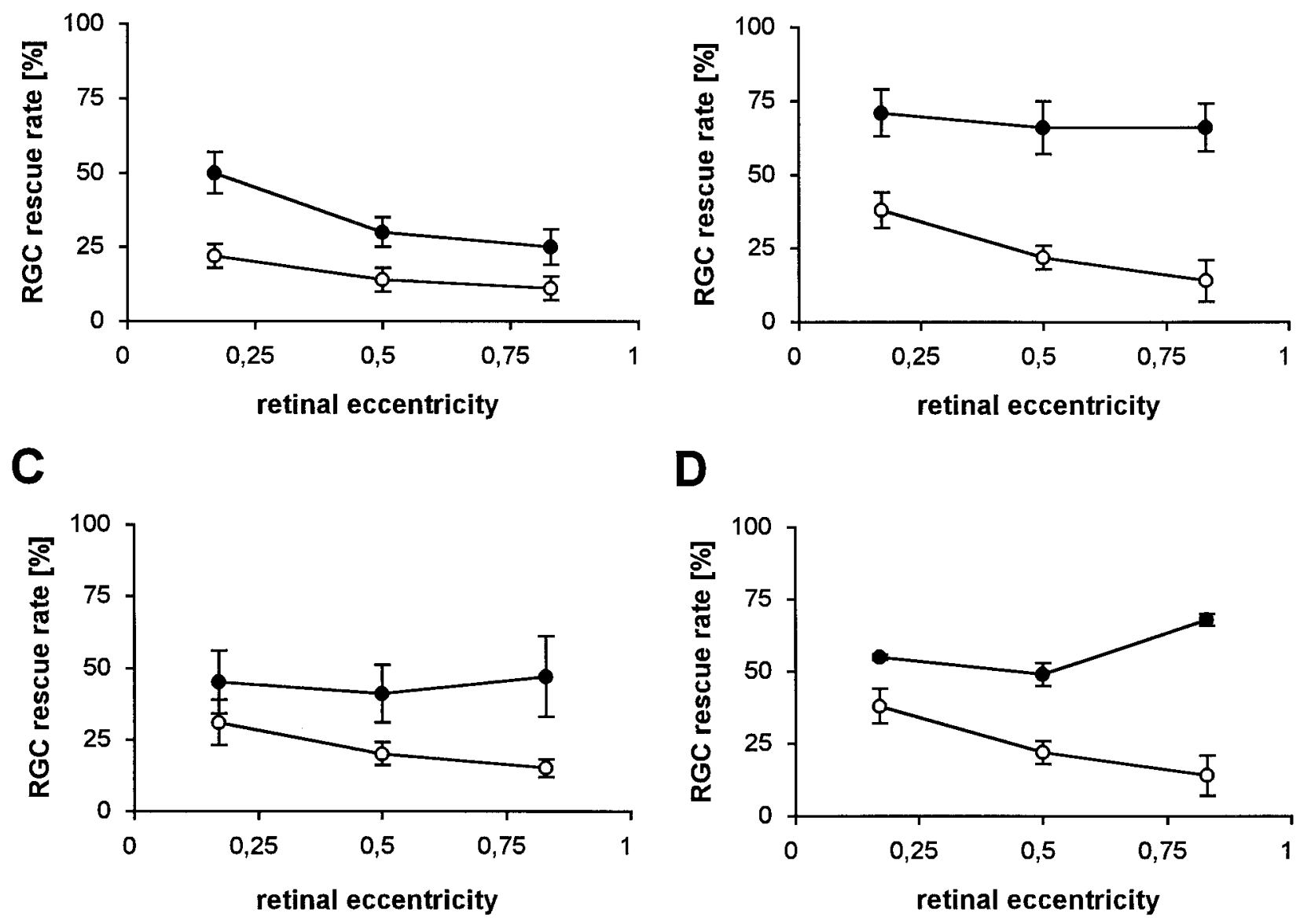

D

Figure 3. Neuroprotection on axotomized RGCs by single treatment with BDNF and combined treatment with BDNF and S-PBN or BDNF and L-NAME depends on retinal eccentricity. RRR $=\left(N_{\text {ther }}-N_{\text {con }}\right) /\left(N_{\text {tot }}-N_{\text {con }}\right) \times 100$, where $N_{\text {tot }}$ is the number of RGCs in unlesioned retinas, $N_{\text {con }}$ is the number of RGCs surviving without therapy, and $N_{\text {ther }}$ is the number of RGCs surviving after a given therapy. Open circles, RRR obtained after single BDNF treatment; filled circles, RRR after combined treatment with BDNF and S-PBN $(A-C)$ or BDNF and L-NAME $(D)$. BDNF treatment: repeated intraocular injections of $200(A), 500(B, D)$, and $2000(C) \mathrm{ng}$ of BDNF on days 4, 7, and 10 after axotomy. S-PBN treatment: $100 \mathrm{mg} / \mathrm{kg}$ S-PBN intraperitoneally twice daily. L-NAME treatment: $25 \mathrm{mg} / \mathrm{kg}$ L-NAME intraperitoneally twice daily. Data are given as mean \pm SEM.

by BDNF can be improved significantly by simultaneous systemic administration of the spin trap molecule S-PBN or of the NOS inhibitor L-NAME. Interestingly, these effects are synergistic, because neither of these two agents influences survival of axotomized RGCs alone.

In the adult mammalian CNS, axotomy often results in retrograde degeneration and death of the injured neurons (cf. GarciaValenzuela et al., 1994). Because of good surgical accessibility, lesion of the retinocollicular projection in the rat serves as a convenient model to study secondary death of injured CNS neurons (Villegas-Pérez et al., 1988, 1993; Eschweiler and Bähr 1993; Mey and Thanos, 1993; Mansour-Robaey et al., 1994). In comparison with lesion models in newborn rats, transection of the adult $\mathrm{ON}$ holds the advantage that injury-induced RGC loss is not confounded by additional RGC degeneration attributable to deprivation of target-derived trophic support during the period of naturally occurring cell death (Carpenter et al., 1986; Fagiolini et al., 1997). For this reason, axotomy of the $\mathrm{ON}$ in the adult rat, a model with well documented spatiotemporal kinetics of cell loss, better reflects the fundamental pathophysiological sequelae of brain injury seen in clinical neurotraumatology.

It is a widely accepted concept that neurotrophins exert their neuroprotective action by hindering the induction of apoptotic cell death (for RGCs, see Cui and Harvey, 1995). In the adult rat, ON transection induces apoptosis in RGCs starting on day 4 and reaching a maximum at approximately day 7 after axotomy (Garcia-Valenzuela et al., 1994; Isenmann et al., 1997). In line with this temporal profile of apoptosis, intraocular injection of BDNF on day 5 rescues a similar number of RGCs as BDNF injections on day 0 or 3 after axotomy (Mansour-Robaey et al., 1994). Therefore, we chose to start BDNF treatment on day 4 after $\mathrm{ON}$ transection to minimize the total number of intraocular injections necessary to obtain effective neuroprotection over $14 \mathrm{~d}$. In the present study, repeated intraocular injections of BDNF on days 4, 7, and 10 after axotomy enhanced RGC survival significantly compared with the vehicle-treated group even at the low dose of $200 \mathrm{ng}$ /injection. This is in clear contrast to other studies, in which vehicle injection alone was effective in promoting survival of axotomized RGCs (Mansour-Robaey et al., 1994; Russelakis-Carneiro et al., 1996) and hence may have disguised the effects of low BDNF doses. This discrepancy could be explained by the less invasive injection procedure we adopted. Using a fine glass microelectrode instead of a 26 gauge needle, we avoided significant injury-induced rescue responses and even ret- 

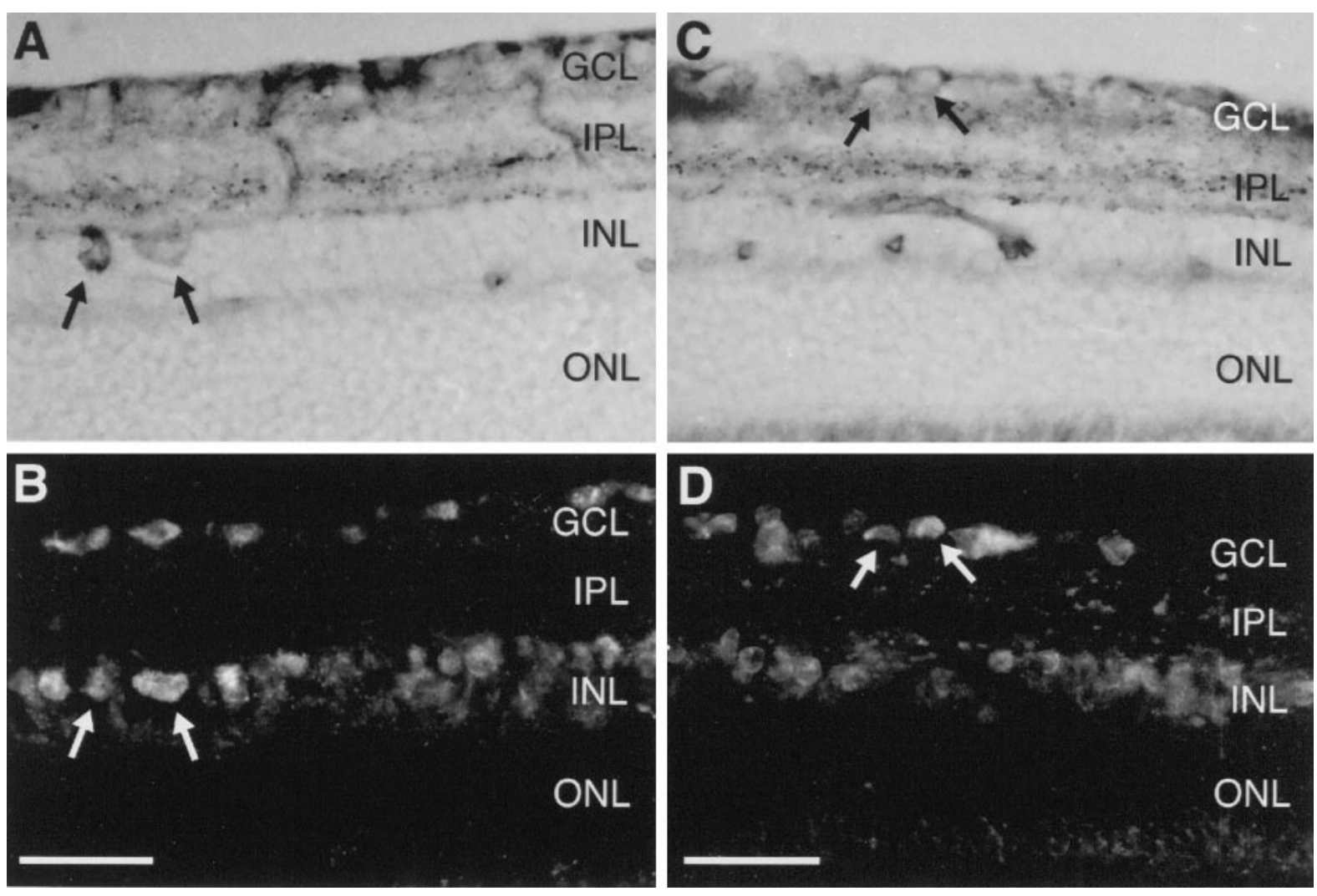

Figure 4. Colocalization of TrkB immunoreactivity and NOS histochemical activity. $A$, NOS histochemical staining using NADPH-diaphorase reactivity as a marker in a radial section of adult rat retina. Two type II amacrine neurons positive for NADPH-diaphorase reactivity are indicated by arrows. $B$, Same field as in $A$ photographed under epiluminescence with a rhodamine filter. TrkB immunoreactivity is revealed by $\mathrm{Cy}-3$ indirect fluorescence (arrows). TrkB immunoreactivity and NADPH-diaphorase reactivity is colocalized clearly in the type II amacrine neurons displayed in $A$ and $B$. $C$, NOS histochemical staining in a radial section of adult rat retina. Two presumptive retinal ganglion cells positive for NADPH-diaphorase reactivity are indicated by arrows. $D$, Same field as in $C$ photographed under epiluminescence with a rhodamine filter. TrkB immunoreactivity is revealed by Cy-3 indirect fluorescence (arrows). TrkB immunoreactivity and NADPH-diaphorase reactivity is colocalized clearly in the indicated neurons. $O N L$, Outer nuclear layer; $I N L$, inner nuclear layer; $I P L$, inner plexiform layer; $G C L$, ganglion cell layer. Scale bar, $35 \mu \mathrm{m}$.

inal shrinkage with repeated injections. We achieved maximal RGC survival after repeated intraocular injections of $500 \mathrm{ng}$ of BDNF. Increasing the dose of BDNF to $2000 \mathrm{ng}$ /injection did not improve RGC survival further. These data indicate that the failure of $\mathrm{BDNF}$ to protect the total RGC population after axotomy is not attributable to suboptimal dosage. As a matter of fact, we observed the trend for a bell-shaped dose-response curve in the neuroprotective action of BDNF. Such a dose-response relation has been described already for BDNF in axotomized motoneurons (Vejsada et al., 1994). It was interpreted as a consequence of a downregulation of the BDNF receptor TrkB after excessive BDNF application, an effect observed in vitro in other CNS neurons (Carter et al., 1995; Frank et al., 1996). An alternative possibility is that BDNF limits its own neuroprotective potential by activating second messenger pathways that are adverse for RGC survival. The rescue rate observed in vivo would then be the net result of these two antagonistic actions. Here we have shown that cells expressing NOS also express the BDNF receptor TrkB and that BDNF administration increases the NADPH-diaphorase reactivity, a marker of NOS expression (Dawson et al., 1991; Darius et al., 1995; Roufail et al., 1995). These results strongly suggest that the concentration of the free radical NO increases after BDNF treatment. Most importantly, specific inhibition of NOS activity by L-NAME potentiates the neurotrophic action of BDNF. It also has been shown that acti- vation of the neuronal form of NOS has negative consequences for neuronal survival after ischemia or excitotoxicity (Kashii et al., 1996; Iadecola et al., 1997) and that BDNF can enhance excitotoxic cell death by enhancing NOS activity in vitro (Samdami et al., 1996). RGCs express glutamate receptors and are known to be sensitive to excitotoxicity (Siliprandi et al., 1992; Brandstatter et al., 1994). The NMDA-receptor antagonist MK801 prevents the fast phase of RGC death after axotomy in the adult cat, suggesting that activation of glutamate receptors is involved in retrograde death of axotomized RGCs (RusselakisCarneiro et al., 1996). However, ON transection is unlikely to cause excitotoxicity in the classical sense (increased glutamate release by injury-induced depolarization as well as leakage of glutamate through injury sites), because the presynaptic input of the RGCs is left untouched by the lesion. Nevertheless, it is conceivable that RGCs become more sensitive to glutamate on a slower time scale resulting in a delayed and progressive "excitotoxicity," which is entirely postsynaptic in origin. We propose that, in analogy to what is observed in vitro, an increased production of $\mathrm{NO}$ attributable to BDNF treatment exacerbates the excitotoxic component of RGC death, thereby limiting the neuroprotective potential of BDNF. This hypothesis would also be consistent with the trend for a bell-shape dose-response curve on RGC survival we observed. It has to be noted that a similar bell-shaped dose-response curve and concomitant induction of 

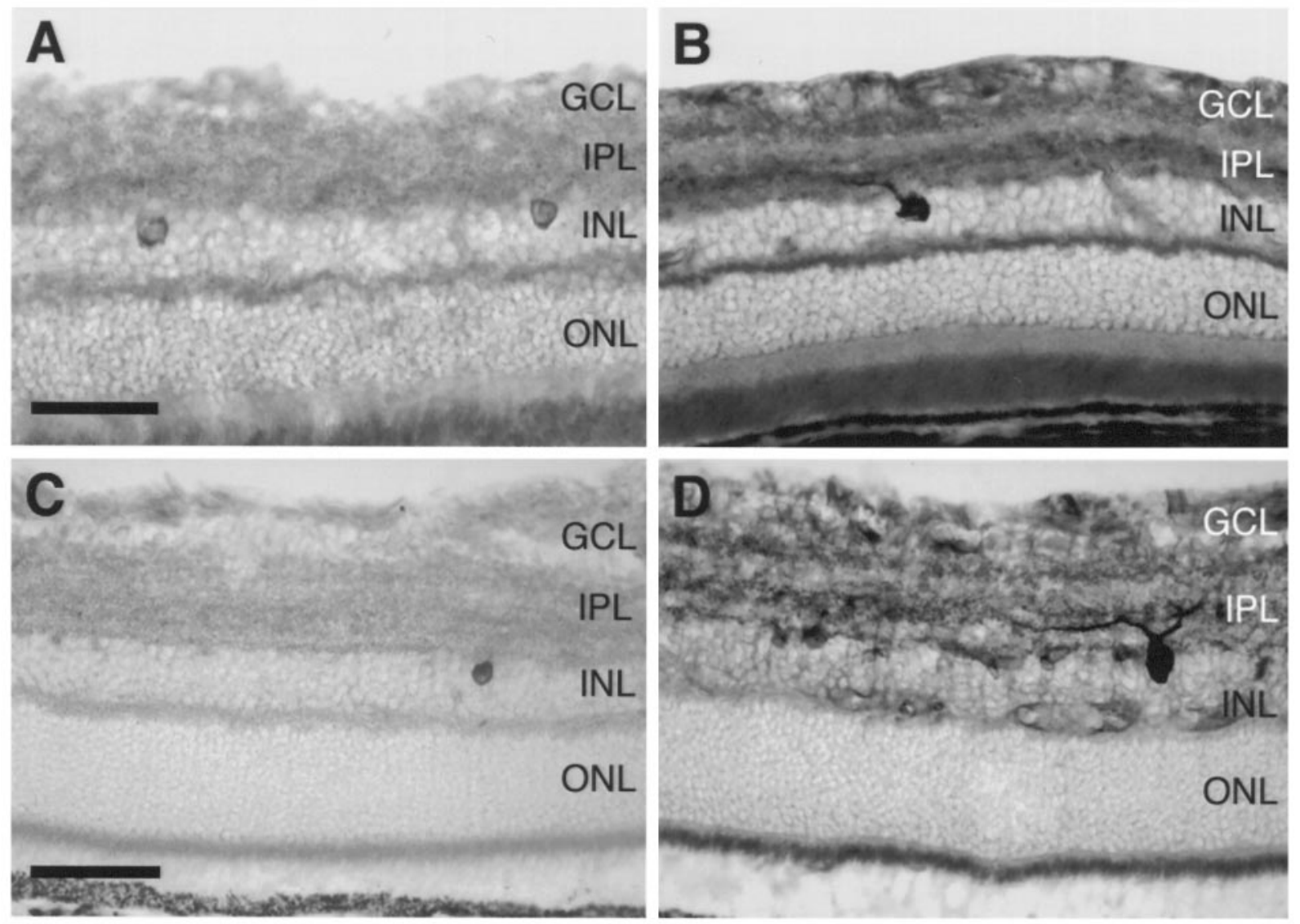

CONTROL

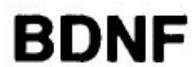

Figure 5. Effect of BDNF on NOS histochemical activity in the adult rat retina using NADPH-diaphorase reactivity as a marker. $A$, $B$, Radial sections of the retinas of an adult rat, which had received three injections of $1000 \mathrm{ng}$ of BDNF every other day in the right eye and was killed $6 \mathrm{~d}$ after the first injection. $A$, Untreated control eye. $B$, BDNF-treated eye of the same rat. $C$, Radial section of an adult rat retina $6 \mathrm{~d}$ after ON transection. $D$, Radial section of an adult rat retina $6 \mathrm{~d}$ after ON transection, which had received a single intraocular injection of $500 \mathrm{ng}$ of BDNF on day 4 after axotomy. Sections were understained to visualize the difference between treated $(B D N F)$ and untreated $(C O N T R O L)$ eyes better. $O N L$, Outer nuclear layer; INL, inner nuclear layer; $I P L$, inner plexiform layer; $G C L$, ganglion cell layer. Scale bar, $35 \mu \mathrm{m}$.

NOS was observed after intraocular injections of a colliculusderived chondroitin sulfate proteoglycan with neurotrophic activity (Huxlin and Bennett, 1995; Huxlin et al., 1995). These data were used originally to propose a supportive role for NO in the retina, but data from the same group subsequently showed that L-NAME potentiates the neurotrophic action of colliculusderived proteoglycan on RGCs in vitro (Nichol et al., 1995), which is in good agreement with the hypothesis we present here.

RGC rescue by BDNF and the combination of BDNF with S-PBN or L-NAME treatment depended on retinal eccentricity. Independent of dosage, neuroprotection by BDNF alone was consistently most effective at the inner retinal radius. When comparing BDNF neuroprotection on axotomized RGCs in our study and other studies, it is striking to note that the RGC rescue rates we obtained were considerably lower than the ones described by other investigators (Mansour-Robaey et al., 1994; Peinado-Ramón et al., 1996). These differences might be explained by the different cell counting protocols. For calculating average RGC densities, these investigators examined three distinct areas per retinal quadrant that were markedly closer to the optic disk than in our study. This may account for the higher RGC rescue rates, because both secondary death of axotomized RGCs and rescue by BDNF treatment is most pronounced in the central retina. The potentiation of BDNF neurotrophic effect by S-PBN or L-NAME, however, was particularly evident at the outer retinal radius when dosage of BDNF was increased. Following the line of argumentation that BDNF enhances injury-induced excitotoxicity in RGCs, these data are in good agreement with studies showing RGCs in the retinal periphery to be more sensitive to excitotoxic lesions (Vorwerk et al., 1996).

Although an enhancement of excitotoxicity by BDNF seems to be the most straightforward explanation for the synergistic action of S-PBN or L-NAME together with BDNF, this hypothesis remains to be proven. In future studies, it will be crucial to assess whether agents blocking glutamatergic neurotransmission show similar synergistic effects with BDNF.

Whatever the biochemical and cellular mechanisms of this synergism are, it is of particular interest that in vitro experiments have also revealed a synergistic action of antioxidants together with a variety of trophic factors on purified oligodendrocytes and to some extent on peripheral neurons (Mayer and Noble, 1994). Thus, the synergistic action of antioxidants and trophic factors might be a rather widespread phenomenon in the nervous system, which could have important clinical implications. In fact, whereas L-NAME blocks all isoforms of NOS and might have severe side effects on blood circulation (Huang et al., 1995), these side effects 
are not seen with S-PBN or analogous spin traps, making them potential candidates for clinical use. Neurotrophins are being tested currently in clinical trials for the treatment of various neurological disorders, such as human neurodegenerative diseases (Yuen and Mobley, 1996; Mitsumoto and Olney, 1996). If our observations obtained in RGCs can be extended to other neuronal populations and injury paradigms, the use of free radical scavengers would provide a promising way to optimize the neuroprotective effects of neurotrophins. This could help in designing new strategies in the treatment of human neurodegenerative diseases, cerebrovascular disorders, and cerebral trauma.

\section{REFERENCES}

Barbacid M (1994) The Trk family of neurotrophin receptors. J Neurobiol 25:1386-1403.

Barde YA, Edgar D, Thoenen H (1982) Purification of a new neurotrophic factor from mammalian brain. EMBO J 1:549-553.

Brandstatter JH, Hartveit E, Sassoe Pognetto M, Wassle H (1994) Expression of NMDA and high-affinity kainate receptor subunit mRNAs in the adult rat retina. Eur J Neurosci 6:1100-1112.

Carmignoto G, Maffei L, Candeo P, Canella R, Comelli C (1989) Effect of NGF on the survival of rat retinal ganglion cells following optic nerve section. J Neurosci 9:1263-1272.

Carpenter P, Sefton AJ, Dreher B, Lim WL (1986) Role of target tissue in regulating the development of retinal ganglion cells in the albino rat effects of kainate lesions in the superior colliculus. J Comp Neurol 251:240-259.

Carter BD, Zirrgiebel U, Barde YA (1995) Differential regulation of p21-ras activation in neurons by nerve growth factor and brain-derived neurotrophic factor. J Biol Chem 270:21751-21757.

Cellerino A, Kohler K (1997) Brain-derived neurotrophic factor/ neurotrophin-4 receptor TrkB is localized on ganglion cells and dopaminergic amacrine cells in the vertebrate retina. J Comp Neurol 386:149-160.

Cellerino A, Pinzón-Duarte G, Carroll P, Kohler K (1997a) BDNF controls the development of dopaminergic innervation in the rodent retina. Soc Neurosci Abstr 23:124.4.

Cellerino A, Carroll P, Thoenen H, Barde YA (1997b) Reduced size of retinal ganglion cell axons and hypomyelination in mice lacking brainderived neurotrophic factor. Mol Cell Neurosci 9:397-408.

Cui Q, Harvey AR (1995) At least two mechanisms are involved in the death of retinal ganglion cells following target ablation in neonatal rats. J Neurosci 15:8143-8155.

Darius S, Wolf G, Huang PL, Fishman MC (1995) Localization of NADPH-diaphorase/nitric oxide synthase in the rat retina: an electron microscopic study. Brain Res 690:231-235.

Dawson TM, Bredt DS, Fotuhi M, Hwang PM, Snyder SH (1991) Nitric oxide synthase and neuronal NADPH diaphorase are identical in brain and peripheral tissues. Proc Natl Acad Sci USA 88:7797-7801.

Eschweiler GW, Bähr M (1993) Flunarizine enhances rat retinal ganglion cell survival after axotomy. J Neurol Sci 116:34-40.

Fagiolini M, Caleo M, Strettoi E, Maffei L (1997) Axonal transport blockade in the neonatal rat optic nerve induces limited retinal ganglion cell death. J Neurosci 17:7045-7052.

Frank L, Ventimiglia R, Anderson K, Lindsay RM, Rudge JS (1996) BDNF down-regulates neurotrophin responsiveness, TrkB protein and TrkB mRNA levels in cultured rat hippocampal neurons. Eur J Neurosci 8:1220-1230.

Garcia-Valenzuela E, Gorczyca W, Darzynkiewicz Z, Sharma SC (1994) Apoptosis in adult retinal ganglion cells after axotomy. J Neurobiol 25:431-438.

Harvey AR, Cui Q, Robertson D (1994) The effect of cycloheximide and ganglioside GM1 on the viability of retinotectally projecting ganglion cells following ablation of the superior colliculus in neonatal rats. Eur J Neurosci 6:550-557.

Huang M, Manning Jr RD, LeBlanc MH, Hester RL (1995) Overall hemodynamic studies after the chronic inhibition of endothelialderived nitric oxide in rats. Am J Hypertens 8:358-364.

Huxlin KR, Bennett MR (1995) NADPH diaphorase expression in the rat retina after axotomy - a supportive role for nitric oxide? Eur J Neurosci 7:2226-2239.
Huxlin KR, Dreher B, Schulz M, Sefton AJ, Bennett MR (1995) Effect of collicular proteoglycan on the survival of adult rat retinal ganglion cells following axotomy. Eur J Neurosci 7:96-107.

Iadecola C (1997) Bright and dark sides of nitric oxide in ischemic brain injury. Trends Neurosci 20:132-139.

Isenmann S, Wahl C, Krajewski S, Reed JC, Bähr M (1997) Upregulation of Bax protein in degenerating retinal ganglion cells precedes apoptotic cell death after optic nerve lesion in the rat. Eur J Neurosci 9:1763-1772.

Jelsma TN, Friedman HH, Berkelaar M, Bray GM, Aguayo AJ (1993) Different forms of the neurotrophin receptor trkB mRNA predominate in the rat retina and optic nerve. J Neurobiol 24:1207-1214.

Johnson JE, Barde YA, Schwab M, Thoenen H (1986) Brain-derived neurotrophic factor supports the survival of cultured rat retinal ganglion cells. J Neurosci 6:3031-3038.

Kashii S, Mandai M, Kikuchi M, Honda Y, Tamura Y, Kaneda K, Akaike A (1996) Dual actions of nitric oxide in $N$-methyl-D-aspartate receptor-mediated neurotoxicity in cultured retinal neurons. Brain Res 711:93-101.

Koh JY, Gwag BJ, Lobner D, Choi DW (1995) Potentiated necrosis of cultured cortical neurons by neurotrophins. Science 268:573-575.

Koistinaho J, Sagar SM (1995) NADPH-diaphorase-reactive neurones in the retina. Prog Retinal Eye Res 15:69-87.

Kuroda S, Katsura K, Hillered L, Bates TE, Siesjo BK (1996) Delayed treatment with phenyl- $N$-tert-butyl nitrone (PBN) attenuates secondary mitochondrial dysfunction after transient focal cerebral ischemia in the rat. Neurobiol Dis 3:149-157.

Leibrock J, Lottspeich F, Hohn A, Hofer M, Hengerer B, Masiakowski P, Thoenen H, Barde YA (1989) Molecular cloning and expression of brain-derived neurotrophic factor. Nature 341:149-152.

Mansour-Robaey S, Clarke DB, Wang YC, Bray GM, Aguayo AJ (1994) Effects of ocular injury and administration of brain-derived neurotrophic factor on survival and regrowth of axotomized retinal ganglion cells. Proc Natl Acad Sci USA 91:1632-1636.

Mayer M, Noble M (1994) N-Acetyl-L-cysteine is a pluripotent protector against cell death and enhancer of trophic factor-mediated cell survival in vitro. Proc Natl Acad Sci USA 91:7496-7500.

Mey J, Thanos S (1993) Intravitreal injections of neurotrophic factors support the survival of axotomized retinal ganglion cells in adult rats in vivo. Brain Res 602:304-317.

Meyer-Franke A, Kaplan M, Pfieger FW, Barres BA (1995) Characterization of the signaling interactions that promote the survival and growth of developing retinal ganglion cells. Neuron 15:805-819.

Mitsumoto H, Olney RK (1996) Drug combination treatment in patients with ALS: current status and future directions. Neurology 47 [Suppl 2]:S103-S107.

Nichol KA, Schulz MW, Bennett MR (1995) Nitric oxide-mediated death of cultured neonatal retinal ganglion cells: neuroprotective properties of glutamate and chondroitin sulfate proteoglycan. Brain Res 697:1-16.

Peinado-Ramón P, Salvador M, Villegas-Pérez MP, Vidal-Sanz M (1996) Effects of axotomy and intraocular administration of NT-4, NT-3, and brain-derived neurotrophic factor on the survival of adult rat retinal ganglion cells. A quantitative in vivo study. Invest Ophthalmol Vis Sci 37:489-500.

Perry VH, Cowey A (1982) A sensitive period for ganglion cell degeneration and the formation of aberrant retino-fugal connections following tectal lesions in rats. Neuroscience 7:583-594.

Rabacchi SA, Bonfanti L, Liu XH, Maffei L (1994) Apoptotic cell death induced by optic nerve lesion in the neonatal rat. J Neurosci 14:5292-5301.

Rickman DW, Brecha NC (1995) Expression of the proto-oncogene, trk, receptors in the developing rat retina. Vis Neurosci 12:215-222.

Roufail E, Stringer M, Rees S (1995) Nitric oxide synthase immunoreactivity and NADPH diaphorase staining are co-localised in neurons closely associated with the vasculature in rat and human retina. Brain Res 684:36-46.

Russelakis-Carneiro M, Silveira LCL, Perry VH (1996) Factors affecting the survival of cat retinal ganglion cells after optic nerve injury. J Neurocytol 23:75-86.

Samdami A, Newcamp C, Resink A, Facchinetti F, Dawson VL, Dawson TM (1996) Nitric oxide mediates potentiation of neurotoxicity by neurotrophins. Soc Neurosci Abstr 22:397.20.

Schulz JB, Henshaw DR, Siwek D, Jenkins BG, Ferrante RJ, Cipolloni 
PB, Kowall NW, Rosen BR, Beal MF (1995a) Involvement of free radicals in excitotoxicity in vivo. J Neurochem 64:2239-2247.

Schulz JB, Matthews RT, Jenkins BG, Brar P, Beal MF (1995b) Improved therapeutic window for treatment of histotoxic hypoxia with a free radical spin trap. J Cereb Blood Flow Metab 15:948-952.

Sievers J, Hausmann B, Unsicker K, Berry M (1987) Fibroblast growth factors promote the survival of adult rat retinal ganglion cells after transection of the optic nerve. Neurosci Lett 76:157-162.

Siliprandi R, Canella R, Carmignoto G, Schiavo N, Zanellato A, Zanoni R, Vantini G (1992) $N$-Methyl-D-aspartate-induced neurotoxicity in the adult rat retina. Vis Neurosci 8:567-573.

Thanos S, Bähr M, Barde YA, Vanselow J (1989) Survival and axonal elongation of adult rat retinal ganglion cells: in vitro effects of lesioned sciatic nerve and brain-derived neurotrophic factor (BDNF). Eur J Neurosci 1:19-26.

Vejsada R, Sagot Y, Kato AC (1994) BDNF-mediated rescue of axoto- mized motor neurones decreases with increasing dose. NeuroReport 5:1889-1892.

Villegas-Pérez MP, Vidal-Sanz M, Bray GM, Aguayo AJ (1988) Influences of peripheral nerve grafts on the survival and regrowth of axotomized retinal ganglion cells in adult rats. J Neurosci 8:265-280.

Villegas-Pérez MP, Vidal-Sanz M, Rasminsky M, Bray GM, Aguayo AJ (1993) Rapid and protracted phases of retinal ganglion cell loss follow axotomy in the optic nerve of adult rats. J Neurobiol 24:23-36.

Vorwerk CK, Kreutz MR, Dreyer EB, Sabel BA (1996) Systemic L-kynurenine administration partially protects against NMDA, but not kainate-induced degeneration of retinal ganglion cells, and reduces visual discrimination deficits in adult rats. Invest Ophthalmol Vis Sci 37:2382-2392.

Yuen EC, Mobley WC (1996) Therapeutic potential of neurotrophic factors for neurological disorders. Ann Neurol 40:346-354. 